\title{
THE USE OF ARTFFICIAL NEURAL NETWORKS IN SUPPORTING THE ANNUAL TRAINING IN 400 METER HUROLES
}

\author{
Janusz Iskra, , A, B, D Krzysztof Przednowek, 2, A, C, D Krzysztof Wiktorowicz,, ${ }^{3, C, D}$ \\ Tomasz Krzeszowski ${ }^{3, D}$
}

\author{
${ }^{1}$ Faculty of Physical Education and Physiotherapy, Opole University of Technology \\ ${ }^{2}$ Faculty of Physical Education, University of Rzeszow \\ ${ }^{3}$ Faculty of Electrical and Computer Engineering, Rzeszow University of Technology

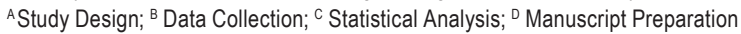 \\ Address for corpespondence: \\ Krzysztof Przednowek, PhD \\ Faculty of Physical Education, University of Rzeszow \\ Towarnickiego 3 str., 35-111 Rzeszów \\ Email: krzprz@ur.edu.pl
}

\begin{abstract}
Ahstract This paper presents an evaluation of the annual cycle for $400 \mathrm{~m}$ hurdles using artificial neural networks. The analysis included 21 Polish national team hurdlers. In planning the annual cycle, 27 variables were used, where 5 variables describe the competitor and 22 variables represent the training loads. In the presented solution, the task of generating training loads for the assumed result were considered. The neural models were evaluated by cross-validation method. The smallest error was obtained for the radial basis function network with nine neurons in the hidden layer. The performed analysis shows that at each phase of training the structure of training loads is different.
\end{abstract}

Key worlds 400 meter hurdles, artificial neural networks, planning training loads

\section{Introduction}

The $400 \mathrm{~m}$ hurdles race is a complex motor and rhythm (technical) athletics race. In terms of motor preparation, the dominant part is endurance of a specific character (anaerobic), supported by a high level of speed and strength. Given the interdisciplinary nature of race training those means, which combine both the technical and the motor aspects of the race, should be used on a very frequent basis (McFarlane, 2000; Iskra, 2012b).

The analysis of training loads in selected disciplines and sports competitions evokes different reactions among scholars and coaches. Some of them claim that the evaluation of an athlete's (or group of athletes) training can be an inspiration to other sportsmen. Others believe that sport is about individual cases where patterns or "average" data have no value (Hiserman, 2008; Iskra, 2012a). 
In the analysis of training loads in athletics, including the $400 \mathrm{~m}$ hurdles, three approaches can be distinguished:

- Analysis of individual training programme - analysis of the intensity and content of the training of the best competitors, usually record holders and champions (Olympic, world and continent) (Alejo, 1993; Iskra, Widera, 2001; Winckler, 2009).

- Statistical analysis of average data - from a group of competitors, who often train over the long term (Brejzer, Wróblewski, Koźmin, 1984; Iskra, 2001; Guex, 2012).

- Mathematical analysis - it is an attempt to use basic science to provide training solutions in competitive sports (Iskra, Ryguła, 2001; Przednowek, Iskra, Cieszkowski, Przednowek, 2015; Wiktorowicz, Przednowek, Lassota, Krzeszowski, 2015).

Each of the above methods of training load analysis has its strengths and weaknesses. For example, the use of artificial neural networks allows a multidimensional analysis of training loads to be carried out, by creating a system that not only analyses the training already carried out, but also lets the coach decide on the size of the training loads to be applied at a given phase in the sports training. The system which is built on the basis of knowledge accumulated over many years of coaching will assist decision-making by providing valuable coaching tips (Przednowek, Iskra, Cieszkowski, Przednowek, 2015). It should be noted that such a system will act as a consultant, since a coach's intuition and the human capacity to analyse reality is still unsurpassed by computer systems.

The aim of this study is to evaluate the annual preparation cycle for $400 \mathrm{~m}$ hurdlers using neural networks. The analyses can be helpful in verifying the views adopted a-priori by coaches, taking into account long-term standards of periodization of training.

\section{Material and methods}

The analysis included 21 Polish hurdlers aged $22.25 \pm 1.96$ years participating in competitions from 1989 to 2011 . The athletes had a high sport level (the result over $400 \mathrm{~m}$ hurdles: $51.26 \pm 1.24 \mathrm{~s}$ ). They were the part of the Polish National Athletic Team Association representing Poland at the Olympic Games, World and European Championships in junior, youth and senior age categories. The best result over $400 \mathrm{~m}$ hurdles in the examined group was equal to $48.19 \mathrm{~s}$. The collected material allowed for the analysis of 48 annual training plans.

In the presented solution the task of generating training loads (GT) for the assumed result were considered. The neural model generates training for the expected result and the parameters of the athlete (Figure 1 and Table 1).

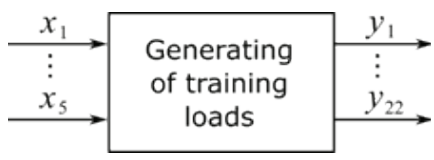

Figure 1. Block diagram of the model for generating training loads

Assistance in planning the training loads in terms of the annual training cycle is reduced to generating training loads recognized as the sum of the training means used throughout the macro-cycle. In planning the annual cycle, 27 variables were used, where 5 describe the competitor and 22 variables represent the training loads. 
Table 1 contains the variables considered and their basic statistics, i.e. the arithmetic mean of $x$, the minimum value $x_{\min }$, the maximum value $x_{\max }$, standard deviation $S D$ and the coefficient of variation $V$.

Table 1. The variables and their basic statis

\begin{tabular}{|c|c|c|c|c|c|c|}
\hline Variables & Description & $x$ & $x_{\min }$ & $x_{\max }$ & $S D$ & $V[\%]$ \\
\hline$x_{1}$ & Expected result on $400 \mathrm{~m}$ hurdles (s) & 51.26 & 48.19 & 53.60 & 1.21 & 2.4 \\
\hline$x_{2}$ & Age (years) & 22.3 & 19.0 & 27.0 & 2.0 & 8.8 \\
\hline$x_{3}$ & Body height $(\mathrm{cm})$ & 185.04 & 177.00 & 192.00 & 4.70 & 2.5 \\
\hline$x_{4}$ & Body weight (cm) & $7 \overline{4} .20$ & 69.00 & 82.00 & 2.71 & 3.6 \\
\hline$x_{5}$ & Current result on 400 m hurdles (s) & 51.91 & 48.70 & 54.70 & 1.37 & 2.6 \\
\hline$y_{1}$ & Maximal speed (m) & $4,184.5$ & $1,530.0$ & $9,650.0$ & 1735.7 & 41.5 \\
\hline$y_{2}$ & Technical speed $(\mathrm{m})$ & $5,244.3$ & 300.0 & $11,790.0$ & $2,921.9$ & 55.7 \\
\hline$y_{3}$ & Technical and speed exercises (m) & $4,253.3$ & 240.0 & $9,450.0$ & $1,752.8$ & 41.2 \\
\hline$y_{4}$ & Speed endurance $(\mathrm{m})$ & $12,655.0$ & $2,850.0$ & $98,900.0$ & $13,744.2$ & 108.6 \\
\hline$y_{5}$ & Specific hurdle (anaerobic) endurance $(\mathrm{m})$ & $12,687.7$ & 800.0 & $23,700.0$ & $5,023.4$ & 39.6 \\
\hline$y_{6}$ & Pace (tempo) runs $(\mathrm{m})$ & $163,796.3$ & $88,000.0$ & $393,800.0$ & $60,101.9$ & 36.7 \\
\hline$y_{7}$ & Aerobic endurance $(\mathrm{m})$ & $363,257.8$ & $151,000.0$ & $692,500.0$ & $97,180.0$ & 26.8 \\
\hline$y_{8}$ & Strength endurance I (m) & $26,070.8$ & $1,000.0$ & $68,990.0$ & $14,923.8$ & 57.2 \\
\hline$y_{9}$ & Strength endurance II (amount) & $5,999.5$ & 300.0 & $40,110.0$ & $6,065.7$ & 101.1 \\
\hline$y_{10}$ & General strength of lower limbs (kg) & $124,060.4$ & $40,100.0$ & $318,610.0$ & $70,776.5$ & 57.1 \\
\hline$y_{11}$ & Directed strength of lower limbs $(\mathrm{kg})$ & $58,379.2$ & $8,240.0$ & $134,400.0$ & $25,912.3$ & 44.4 \\
\hline$y_{12}$ & Specific strength of lower limbs (kg) & $41,659.9$ & $7,810.0$ & $272,750.0$ & $40,685.1$ & 97.7 \\
\hline$y_{13}$ & Trunk strength (amount) & $46,438.7$ & $6,100.0$ & $233,680.0$ & $44,496.7$ & 95.8 \\
\hline$y_{14}$ & Upper body strength $(\mathrm{kg})$ & $3,305.8$ & 760.0 & $29,610.0$ & $4,151.1$ & 125.6 \\
\hline$y_{15}$ & Explosive strength of lower limbs (amount) & 824.0 & 282.0 & $2,138.0$ & 350.9 & 42.6 \\
\hline$y_{16}$ & Explosive strength of upper limbs (amount) & 443.7 & 60.0 & $1,360.0$ & 277.9 & 62.6 \\
\hline$y_{17}$ & Technical exercises - walking pace (min) & 424.9 & 45.0 & 816.0 & 233.3 & 54.9 \\
\hline$y_{18}$ & Technical exercises running pace (min) & 518.8 & 150.0 & $1,500.0$ & 271.3 & 52.3 \\
\hline$y_{19}$ & Runs over $1-3$ hurdles (amount) & 95.6 & 23.0 & 231.0 & 40.3 & 42.2 \\
\hline$y_{20}$ & Runs over 4-7 hurdles (amount) & 169.5 & 8.0 & 336.0 & 69.3 & 40.9 \\
\hline$y_{21}$ & Runs over 8-12 hurdles (amount) & 151.6 & 32.0 & 377.0 & 87.7 & 57.8 \\
\hline$y_{22}$ & Hurdle runs in varied rhythm (amount) & 857.0 & 36.0 & $1,680.0$ & 360.2 & 42.0 \\
\hline
\end{tabular}

This study uses artificial neural networks in the form of the multilayer perceptron (MLP) and the radial basis function (RBF). Multilayer perceptron is the most common type of artificial neural networks (Bishop, 2006). During MLP training, exponential and hyperbolic tangent function were used as the activation functions of hidden neurons. The feature of RBF network is the fact that the hidden neuron performs as a basis function that changes radially around the selected center. All the analysed networks have one hidden layer. For the implementation of neural networks, StatSoft STATISTICA software was used (Statsoft, 2011). The cross-validation method was implemented using Visual Basic language.

The models presented in this paper were evaluated by leave-one-out cross-validation (LOOCV) (Arlot, Celisse, 2010). The idea of this method is based on the separation from data set $n$ subsets, where $n$ is the number of all patterns. Each subset is formed by removing from the data set only one pair, which becomes the testing pair. The cross validation error $(C V E)$ is expressed by the formula: 


$$
\begin{gathered}
\operatorname{NRMSE}_{j}=\frac{\sqrt{\frac{1}{n} \sum_{i=1}^{n}\left(y_{i j}-\hat{y}_{-i j}\right)^{2}}}{y_{j_{\max }}-y_{j_{\min }}} \cdot 100, \\
C V E=\frac{1}{r} \sum_{j=1}^{r} N R M S E_{j},
\end{gathered}
$$

where: $N R M S E_{j}$ - the normalized root mean square error for the $j$-th output, $r$ - the number of outputs, $n=48$ - the number of patterns, $y_{i j}$ - the real (measured) value, $\hat{y}_{-i j}$ - the output value constructed in the $i$-th step of crossvalidation based on a data set containing no testing pair $\left(x_{i}, y_{i}\right), y_{j \max }$ - the maximal value of the $j$-th training load, $y_{\text {jmin }}$ - the minimal value of the $j$-th training load.

\section{Results with discussion}

The main aspect of supporting sport training presented in this study is generating training loads for selected parameters of an athlete. In this way, the proposed approach allows, among others, for individualization of a training plan (Bompa, Haff, 1999).

Taking into consideration various topologies of networks, an optimal multi-layer perceptron was calculated. This model has 5 neurons in the hidden layer and hyperbolic tangent activation function. Compared to the best model with an exponential function it is superior because it generates the error smaller by $0.2 \%$. The best perceptron generates the annual training plan with the error CVE $=19.95 \%$ (Figure 2). The optimal RBF network has 5 hidden neurons and CVE $=19.34 \%$. This result is better than that obtained for the MLP networks. Therefore, as the optimal method, the RBF network with five hidden neurons was used.

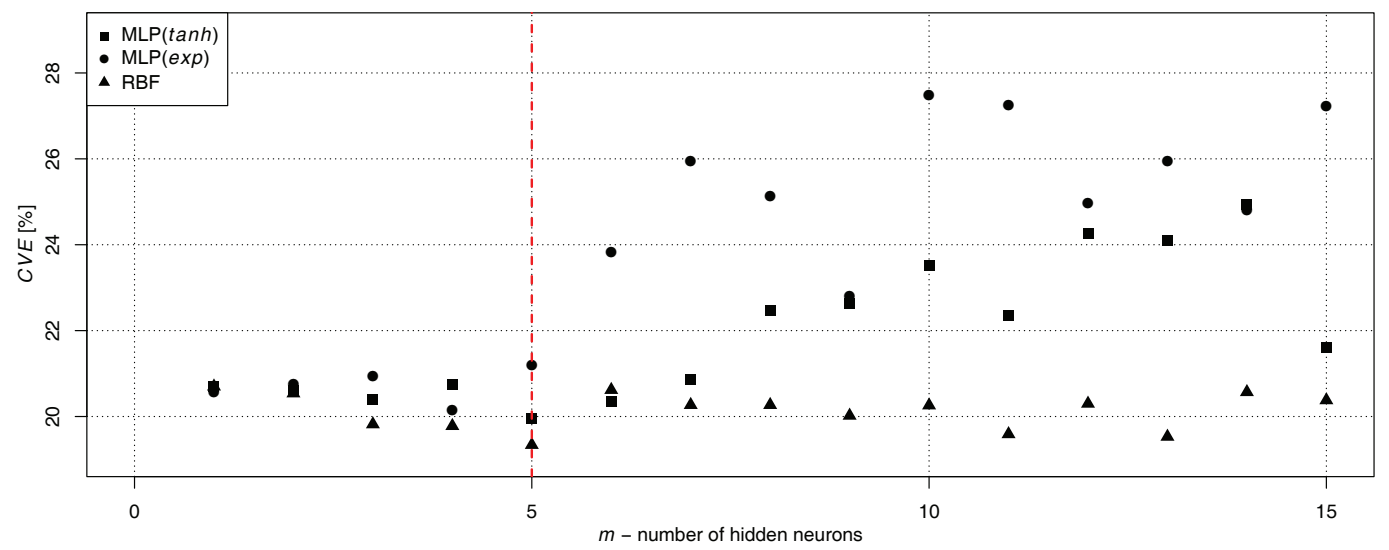

Figure 2. CVE error for artificial neural networks

The optimal model was analysed to determine the errors generated for different outputs, which allowed to identify which training means are generated with the smallest error (Table 2). The detailed analysis showed that $y_{4}, y_{9}$ and $y_{14}$ 
(speed endurance, strength endurance II, upper body strength) are generated with the highest accuracy (NRMSE $E_{j}$ at the level of $14-15 \%)$, whereas the output representing technical exercises in march $\left(y_{17}\right)$ has the largest error $(30 \%)$.

Table 2. Errors for the outputs of the RBF network

\begin{tabular}{|c|c|c|c|c|c|c|c|c|c|c|c|}
\hline Variable & $y_{1}$ & $y_{2}$ & $y_{3}$ & $y_{4}$ & $y_{5}$ & $y_{6}$ & $y_{7}$ & $y_{8}$ & $y_{9}$ & $y_{10}$ & $y_{11}$ \\
\hline$N R M S E_{j}[\%]$ & 17.28 & 20.90 & 17.97 & 14.73 & 20.44 & 20.26 & 18.55 & 15.37 & 14.11 & 21.74 & 18.02 \\
\hline Variable & $y_{12}$ & $y_{13}$ & $y_{14}$ & $y_{15}$ & $y_{16}$ & $y_{17}$ & $y_{18}$ & $y_{19}$ & $y_{20}$ & $y_{21}$ & $y_{22}$ \\
\hline $\operatorname{NRMSE}_{j}[\%]$ & 16.02 & 20.25 & 14.63 & 20.81 & 21.41 & 29.95 & 21.58 & 19.96 & 20.55 & 22.38 & 18.47 \\
\hline
\end{tabular}

The chosen neural network was tested by generating training plans for a hypothetical athlete (age: 21 years, body height: $185 \mathrm{~cm}$, weight $75 \mathrm{~kg}$ ). In every case the result was expected to improve by one second as a result of accepting the output from 56 to 49 seconds.

Training loads forming speed $\left(y_{1}-y_{3}\right)$ are very similar in nature (Figure 3$)$. At the beginning of an athlete's career, the highest content of these loads can be noted, and with their increasing competitive level, a decrease in loads (until the competitor achieves $51 \mathrm{~s}$ ), can be observed. While obtaining the best results, the rates of training loads influencing speed go up with increasing sports level.

The $400 \mathrm{~m}$ hurdles race is still a sprint distance so the need for speed training is the priority, but requires a variety of assessments in terms of a year-round and long-term cycle of preparation. For "high-speed" hurdlers short races can be an important part of training, but in the group of other hurdlers ("endurance" and "rhythm" type) maximum speed exercises are only additional to the basic training (Iskra, 2012b; Balsalobre-Fernández, Tejero-González, del Campo-Vecino, Alonso-Curiel, 2013). Analyses show a characteristic tendency to reduce the importance of speed training in the middle phase of the development of a sports career with a return to speed exercises for the highest performance $\left(y_{1}-y_{3}\right)$. This fact can be explained, on the one hand, by a particular emphasis on anaerobic exercise during the period of "growing up" to athletic championship level, and, on the other hand, by shortening distance of training at the final, highest phase. Such tendencies can be observed in the analysis of the content of training of the best Polish hurdlers who have been competing for many years (Iskra, Widera, 2001).

In the group of endurance training loads $\left(y_{4}-y_{7}\right)$ two trends of changes depending on the level of training (Figure 3) were observed. The content of exercises that form speed endurance $\left(y_{4}\right)$ and aerobic endurance $\left(y_{7}\right)$ increases when the athlete obtains average results (up to 52-51 s), while at a later phase, when his/her form is improving, the value of these loads is consistently declining. Other training loads related to strength have similar tendencies to the speed loads. The values of these loads $\left(y_{5}, y_{6}\right)$ at the beginning gradually decrease until the competitor achieves $52 \mathrm{~s}$. The values start rising with the increasing competitive level of the athlete.

The whole essence of the running training of a 400 m hurdler, supported by research in the physiology of physical effort, lies in the statement above. The $400 \mathrm{~m}$ hurdles distance is a typical anaerobic effort, for which the value of lactate amounts to $20 \mathrm{mmol} / \mathrm{l}$ (Ward-Smith, 1997; Gupta, Goswami, Mukhopadhyay, 1999; Zouhal et al., 2010). Therefore, the best, in terms of motor skills, competitors use specific training means at the prime time of their career. Including "alternative" sets of exercises of reduced intensity in this period (the so-called "tempo endurance" system) can be explained by the difficult conditions for Polish winter training, which encourages coaches to reduce the speed of races in favor of training intensity (Iskra, Przednowek, 2016). 
Another group of generated training loads included exercises developing strength endurance $\left(y_{8}, y_{9}\right)$. In both cases, an increase in the work performed in the early phases of a career can be observed, whereas after reaching the value of $51 \mathrm{~s}$ the number of these exercises decreases. Many coaches believe that endurance-strength exercises, are typical of the best athletes (Hiserman, 2008). The test results did not confirm this thesis. Perhaps the commonly accepted theories in respect of training periodization should be verified.

The most diverse group of training loads used in the training of a $400 \mathrm{~m}$ hurdler are exercises for strength $\left(y_{10}-y_{16}\right)$ (Figure 3-4). This group includes seven types of loads measured in kilograms, and the number of repetitions. In preparing the competitor, the right strength training, primarily of the lower limbs, is very important. In the generated training loads, the first three relate to the strength of the lower limbs (general strength $-y_{10}$; direct strength $-y_{11}$; specific strength $-y_{12}$ ). Training loads $y_{10}-y_{11}$ at the beginning of an athlete's career increase in content, until the athlete achieves $51 \mathrm{~s}$. The content of these exercises remains at a more or less stable level as the athlete's competitive level increases. Characteristic changes in the content of training relate to specific strength $\left(y_{12}\right)$, which is relevant only in the training of hurdlers. The value of the training load in the early phases of a career oscillates at the highest value, while its value declines after achieving $51 \mathrm{~s}$. When analysing the trunk strength $\left(y_{13}\right)$ it can be observed that the loads increase up to a result of $51 \mathrm{~s}$; they then decrease until the athlete reaches the championship level. Different in nature are changes in loads of the upper limbs and the shoulder girdle $\left(y_{14}\right)$. These loads decrease at the beginning of an athlete's career while at a higher level of training their value gradually increases with the increasing competitive level.
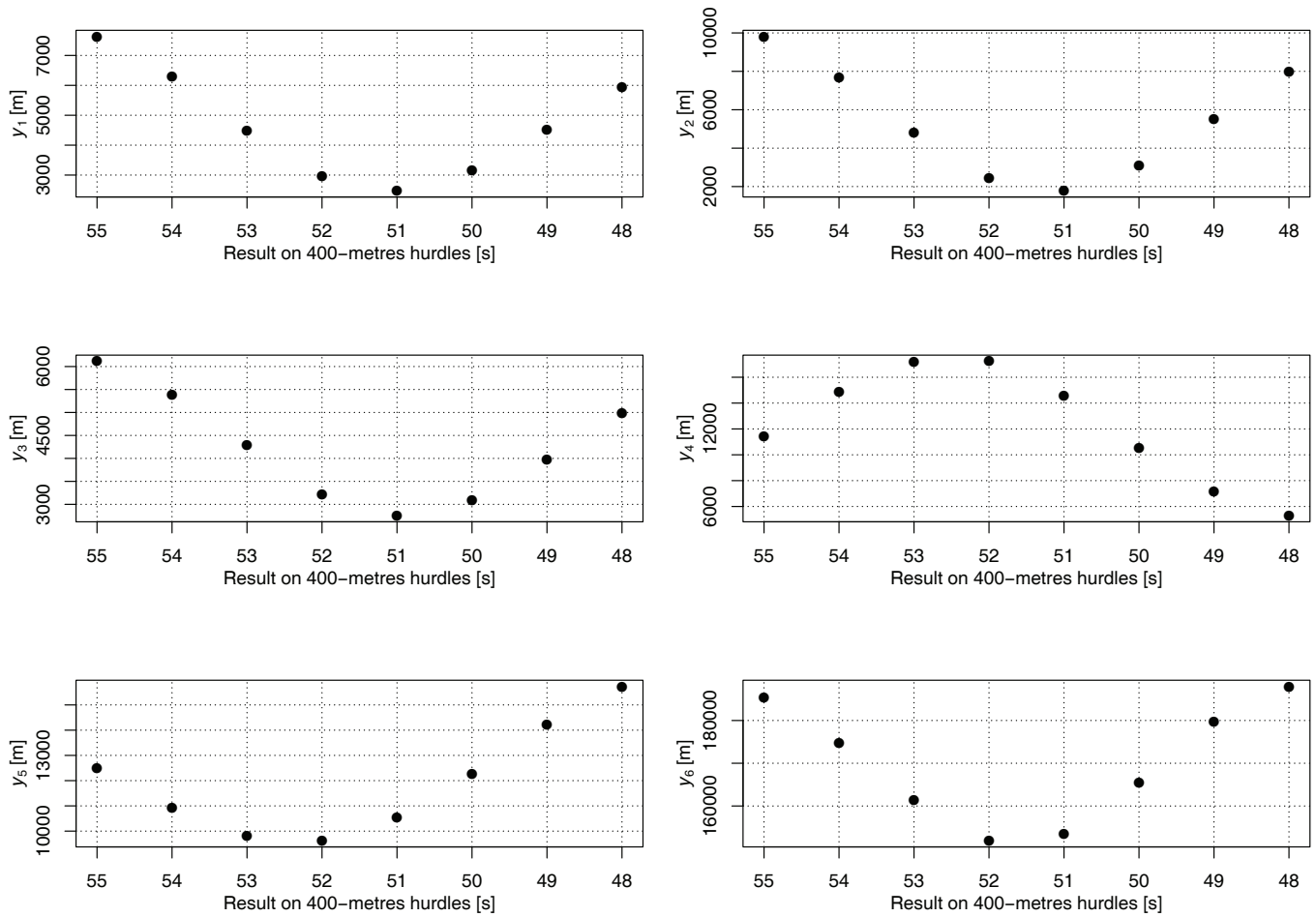

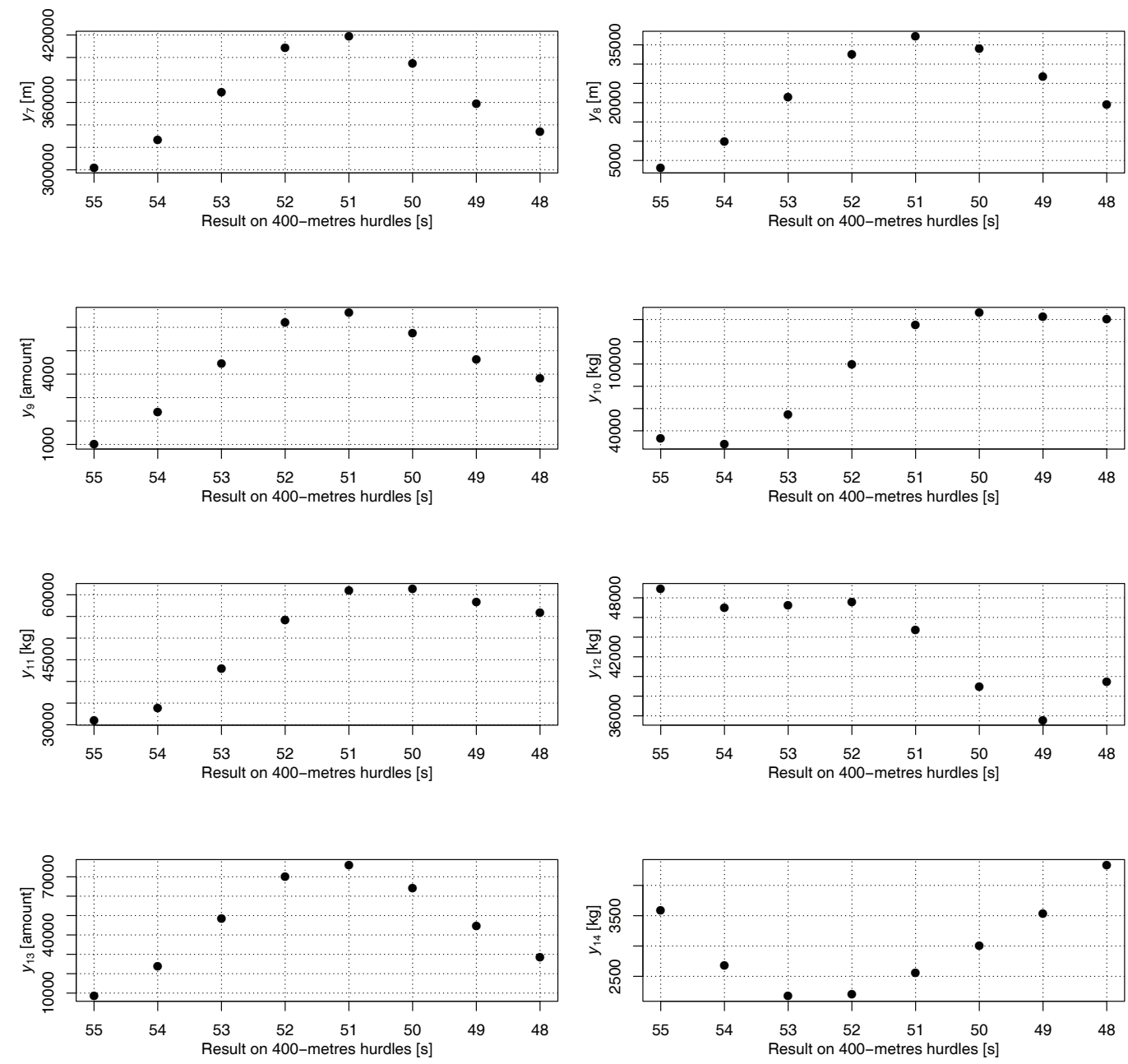

Figule 3. Training loads $y_{1}-y_{14}$ generated for results from $55 \mathrm{~s}$ to $48 \mathrm{~s}$

Changes in the content of strength and speed exercises of lower and upper limbs $\left(y_{15}, y_{16}\right)$ have similar variability (Figure 4). At first the changes are very small and the level of the loads is relatively small. The content of these loads is increasingly going up only when the competitor achieves results of $52 \mathrm{~s}$. At the championship level the loads stabilize at a high level.

Improvement of the strength capacity in athletics speed races is now one of the trends in searching opportunities to improve results. It is mentioned by the classics of the theory of sports training (Bompa, Haff, 1999; Sozański, Sadowski, Czerwinski, 2015) and the best coaches of this sport (Smith, 2005; Husbands, 2013). The results of the analyses in the group of the best Polish hurdlers do not confirm entirely this trend. Only the basic strength training exercises of the lower limbs from the "average" level remain at the same high level $\left(y_{10}-y_{11}\right)$. Attention should be 
paid to the growing importance of strength training exercises of a dynamic character, which at the highest phase of athletic championship take up significant content of training. This applies to both lower limbs and upper muscle groups. The emphasis on dynamic exercises is consistent with the speed-strength character of sprint effort.

The last group (Figure 4) of generated training loads are exercises shaping the technique and the so-called "hurdles rhythm" (runs in standard conditions over 1-12 hurdles) - $\left(y_{17}-y_{22}\right)$. Changes in the content of training of technical exercises in walking $\left(y_{17}\right)$ and hurdling exercises over 8-12 hurdles $\left(y_{21}\right)$ are very similar. Training loads grow until the athlete obtains a score between 52 and $51 \mathrm{~s}$, then with increasing competitive level their content decreases. In contrast, while considering the technical exercises performed in the run $\left(y_{18}\right)$, it is noted that the largest content is observed at the lowest competitive level and along with its growth the content of the loads increases. At the highest competitive level the content of this load increases slightly. Taking into consideration the hurdling exercises over 4-7 hurdles $\left(y_{21}\right)$ it is noted that the increase in competitive level follows the increase of the content of the loads. At the championship level the value of these exercises decreases. The analysis also showed that jumping 1-3 hurdles $\left(y_{19}\right)$ and races with a varied rhythm $\left(y_{22}\right)$ have very similar dynamics throughout the duration of an athlete's career. Initially, the content diminishes and at the championship level the content is gradually increasing.

Training sessions including hurdles are specific for this competition form of training. Most analyses of training loads of a 400 m hurdler concentrate on this group of training means (Brejzer, Wróblewski, Koźmin, 1984; Iskra, 2001). The results indicate, however, differences in application of particular groups of exercises. At the initial phase of training, jumps over 1-3 hurdles and specific exercises in a diverse rhythm are preferred. This part of the analysis fully confirms the trends in training young people (Otsuka, Ito, Ito, 2010; Iskra, 2012a). During further development of a sporting career the best Polish hurdlers prefer jumping 4-12 hurdles which, according to coaches, is the basis for success in this athletics races (McFarlane, 2000; Iskra, 2012; Hiserman, 2008). From the point of view of training, the changes in the selection of hurdling exercises at the highest levels are interesting. Hurdlers at the championship level, give up the longer forms of running, returning to the exercises from the beginning of a sports career.
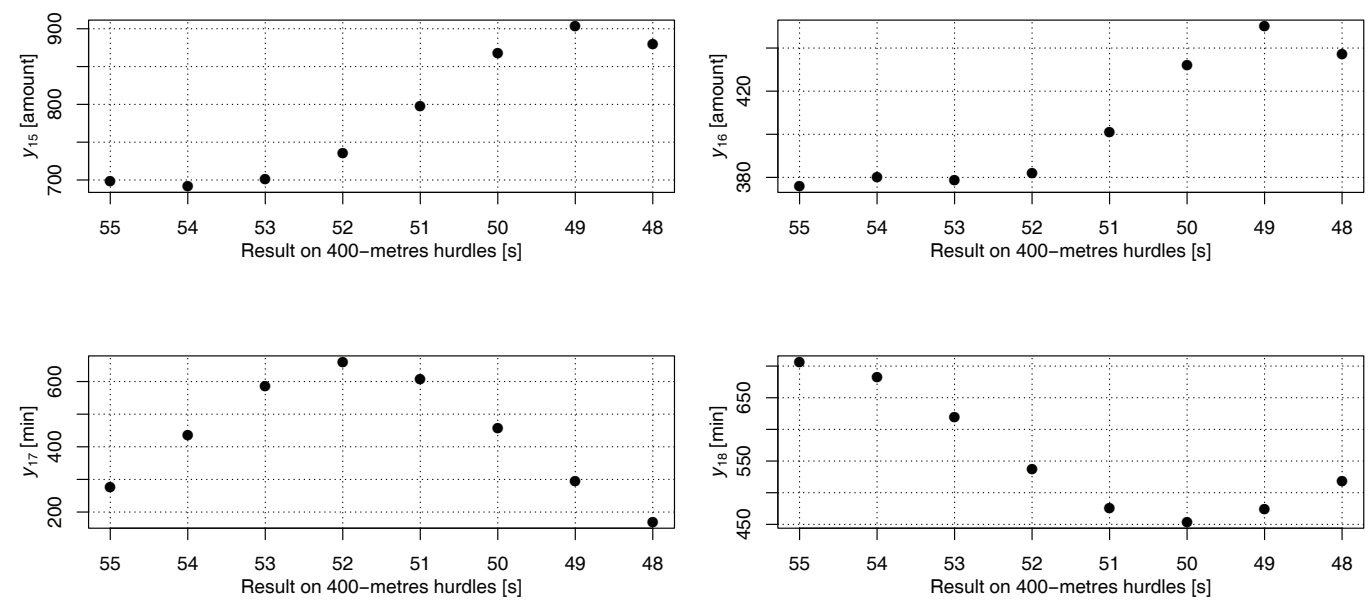

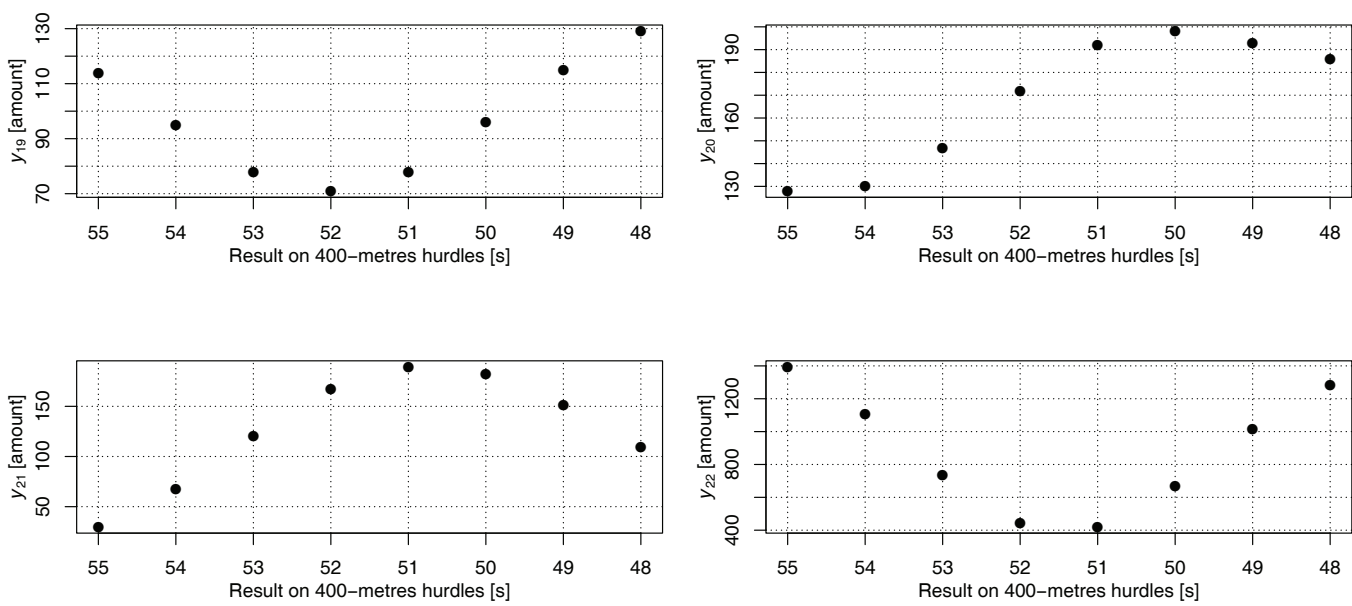

Figure 3. Training loads $y_{15}-y_{22}$ generated for results from $55 \mathrm{~s}$ to $48 \mathrm{~s}$

\section{Conclusions}

Trend analysis of training loads shows non-linear changes in the content of training. In most cases, at some phase, there is an increase of training loads, and at a later phase of an athletic career there is a reduction or stabilization at a similar level. This observation is important in the organization of a hurdler's training. The analysis allows to formulate the following conclusions:

1. Analysis of training loads in the multi-cycle training of $400 \mathrm{~m}$ hurdlers made it possible to establish the main training emphasis of 22 analysed groups of exercises.

2. The results show that at each phase of training (basic training, the period of obtaining significant outcomes and the period of athletic mastery) the structure of training loads is different.

3. The initial period is dominated by speed and jumping exercises, during the development of athletic mastery various forms of strength endurance and runs over 8-12 hurdles are focused on, and at the time of obtaining record results anaerobic endurance is predominant, along with basic strength exercises and runs over 4-7 hurdles.

4. Long-term analyses of the training loads of the best Polish $400 \mathrm{~m}$ hurdlers can be helpful in organizing training of competitors at different levels.

Future work will include, among others, construction of the interface for coaches and competitors. In addition, other methods of machine learning will be verified in the implementation of generating training. The authors are also planning to construct models for specific training periods, e.g. direct pre-competition preparation.

\section{Acknowledgments}

This work has been supported by the Polish Ministry of Science and Higher Education within the research project "Development of Academic Sport" in the years 2016-2018, project no. N RSA4 00554. 


\section{References}

Alejo, B. (1993). Weight training for the $400 \mathrm{~m}$ hurdler. Track Technique, 123, 3915-3918.

Arlot, S., Celisse, A. (2010). A survey of cross-validation procedures for model selection. Statistics Surveys, 4, 40-79.

Balsalobre-Fernández, C., Tejero-González, C.M., del Campo-Vecino, J., Alonso-Curiel, D. (2013). The Effects of a Maximal Power Training Cycle on the Strength, Maximum Power, Vertical Jump Height and Acceleration of High-Level 400-Meter Hurdlers. Journal of Human Kinetics, 36, 119-126.

Bishop, C. (2006). Pattern recognition and machine learning. Springer.

Bompa, T.O., Haff, G. (1999). Periodization: Theory and methodology of training. Human Kinetics Champaign.

Brejzer, W., Wróblewski, J.P., Koźmin, R. (1984). 400 m s/b. Raspriedelienie treninrowocznych nagruzok. Legkaja Atletika, 12, 12-13.

Guex, K. (2012). Kinematic Analysis of the Women's 400 m Hurdles. New Studies in Athletics, 27 (1/2), 41-51.

Gupta, S., Goswami, A., Mukhopadhyay, S. (1999). Heart rate and blond lactate in $400 \mathrm{~m}$ flat and $400 \mathrm{~m}$ hurdle running: a comparative study. Indian Journal of Physiology and Pharmacology, 43 (3), 361-366.

Hiserman, J. (2008). A program design method for sprint \& hurdle training. Jim Hiserman, C.S.C.S.

Husbands, C. (2013). Sprinting: Training, Techniques and Improving Performance. The Crowood Press, Ramsbury.

Iskra, J, Ryguła, R. (2001). The optimization of training loads in high class hurdlers. Journal of Human Kinetics, 6, 59-72.

Iskra, J. (2001). Morfologiczne i funkcjonalne uwarunkowania rezultatów w biegach przez płotki. Katowice: AWF.

Iskra, J. (2012a). Badania naukowe w biegach przez płotki. Katowice: AWF.

Iskra, J. (2012b). Athlete typology and training strategy in the $400 \mathrm{~m}$ hurdles. New Studies in Athletics, 27, 1-2, 27-37.

Iskra, J., Przednowek, K. (2016). Influence of fatigue in the selected kinematic parameters of hurdle clearance in 400 metre race in search of an accurate training test. The $34^{\text {th }}$ International Conference on Biomechanics in Sports, Tsukuba, 687-690.

Iskra, J., Walaszczyk, A., Mehlich, R. (2006). Principles of $400 \mathrm{~m}$ hurdle training. Track Coach, 177, 5641-5645.

Iskra, J., Widera, J. (2001). The training preparation of the world junior $400 \mathrm{~m}$ hurdles champion. Track Coach, 156, 4980-4984, 4997. McFarlane, B. (2000). The Sciences of Hurdling. Canadian Track and Field Association, Ottawa.

Otsuka, M., Ito, M., Ito, A. (2010). Analysis of hurdle running at various inter-hurdle distances in an elementary school PE class. International Journal of Sport and Health Science, 8, 35-42.

Przednowek, K., Iskra, J., Cieszkowski, S., Przednowek, K.H. (2015). Planning training loads to develop technique and rhythm in the $400 \mathrm{~m}$ hurdles using RBF network. In: Proceedings of the $3^{\text {rd }}$ International Congress on Sports Sciences Research and Technology Support (icSPORTS 2015), (pp. 245-249). Lisbon, Portugal.

Quinn, M.D. (2010). External effects in the 400-m hurdles race. Journal of Applied Biomechanics, 26 (2), 171-179.

Smith, M. (2005). High performance sprinting. The Crowood Press, Ramsbury.

Sozański, H., Sadowski, J., Czerwiński, J. (2015). Podstawy teorii i technologii treningu sportowego. Tom II. Warszawa-Biała Podlaska: Akademia Wychowania Fizycznego.

StatSoft Inc. (2011). STATISTICA (data analysis software system), version 10. www.statsoft.com.

Ward-Smith, A. (1997). A mathematical analysis of the bioenergetics of hurdling. Journal of Sport Sciences, 15, 517-526.

Wiktorowicz, K., Przednowek, K., Lassota, L., Krzeszowski, T. (2015). Predictive Modeling in Race Walking. Computational Intelligence and Neuroscience, Article ID 735060.

Winckler, G. (2009). Producing extraordinary sprint runners. In: I. Mujika (ed.), Tapering and peaking for optimal performance. (pp. 155-160). Champaign: Human Kinetics.

Zouhal, H., Jabbour, G., Jacob, B., Duvigneau, D., Botcazou, M., Ben Abderrahaman, A., Prioux, J., Moussa, E. (2010). Anaerobic and aerobic energy system contribution to $400-\mathrm{m}$ flat and $400-\mathrm{m}$ hurdles track running. Journal of Strength and Conditioning Research, 24 (9), 2309-2315.

Cite this article aS: Iskra, J., Przednowek, K., Wiktorowicz, K., Krzeszowski, T. (2017). The Use of Artificial Neural Networks in Supporting the Annual Training in 400 meter Hurdles. Central European Journal of Sport Sciences and Medicine, 17 (1), 15-25. DOI: 10.18276/cej.2017.1-02. 